\title{
Recessively inherited brachydactyly type C
}

\author{
MICHAEL BARAITSER AND JOHN BURN
}

From the MRC Clinical Genetics Unit, Institute of Child Health, 30 Guilford Street, London WC1N 1EH, and The Hospital for Sick Children, Great Ormond Street, London WC1N $3 J H$.

SUMMARY We report a brother and sister, the children of unaffected consanguineous Iraqi parents, with type $\mathrm{C}$ brachydactyly.

The Bell classification of brachydactyly ${ }^{1}$ divides this group of conditions into types A1 to A5, B, C, D, and E. Fitch ${ }^{2}$ in 1979 suggested that types A4 to A5 be omitted because the latter is indistinguishable radiologically from type $B$, while type $A 4$ is possibly a mild expression of A1. She suggested that type E should be further subdivided depending on which metacarpals are involved. The table summarises the classification. There have been numerous reports of isolated brachydactyly occurring as a familial trait; these reports have suggested an autosomal dominant pattern of inheritance.

We report two sibs with type C brachydactyly, whose parents were consanguineous and unaffected, suggesting autosomal recessive transmission in this family.

\section{Case reports}

The parents, first cousins, born in Iraq, were normal on clinical examination. Their first child had died, but clinical details were not available. Their surviving children, a girl of 7 years and a boy of 14 months, are described. The abnormal signs in both sibs were

Received for publication 29 September 1982.

TABLE Current classification of brachydactyly.

\begin{tabular}{|c|c|c|}
\hline Types & Bones involved & Digits affected \\
\hline Al & Middle phaianges & $\begin{array}{l}\text { All can be affected; } \\
\text { 3rd least affected making } \\
\text { it longer than 4th }\end{array}$ \\
\hline A2 & Middle phalanges & Especially digit 2 \\
\hline A3 & Middle phalanges & Especially digit 5 \\
\hline B & $\begin{array}{l}\text { Middle and terminal } \\
\text { phalanges }\end{array}$ & Digits 2-5 \\
\hline $\mathbf{C}$ & $\begin{array}{l}\text { Middle phalanges and } \\
\text { sometimes proximal. } \\
\text { (Affected phalanges may } \\
\text { be bifid and/or have } \\
\text { radial projection.) }\end{array}$ & $\begin{array}{l}\text { Most severe in digits } 2-3 \\
\text { (4th is longest digit or } \\
\text { equal to } 3 \text { rd) }\end{array}$ \\
\hline & Metacarpal & Thumb \\
\hline $\mathbf{D}$ & $\begin{array}{l}\text { Distal phalanx short } \\
\text { and broad }\end{array}$ & Thumb \\
\hline $\mathbf{E}$ & Short metacarpals & One or more digits \\
\hline
\end{tabular}

Adapted from Bell ${ }^{1}$ and Fitch. ${ }^{2}$ confined to the hands and feet (figs 1-4). Both were i of normal stature and development. In the hands, i digits 1,2 , and 3 were short, resulting in a con- $\vec{N}$ figuration in which the ring or 4th finger was the $\infty$ longest. In the feet, the same abnormalities were 을 present. $X$-rays showed the shortening to be the result of abnormalities of the middle phalanges with $\frac{7}{0}$ relative sparing of the $4 \mathrm{th}$. In the hands, the thumbs were short not only because of a short proximal $\overrightarrow{0}$ phalanx, which is equivalent to the middle phalanx of the fingers, but also because the first metacarpals were short. The feet showed similar changes. In the older child, the proximal phalanges of the big toes were bifid.

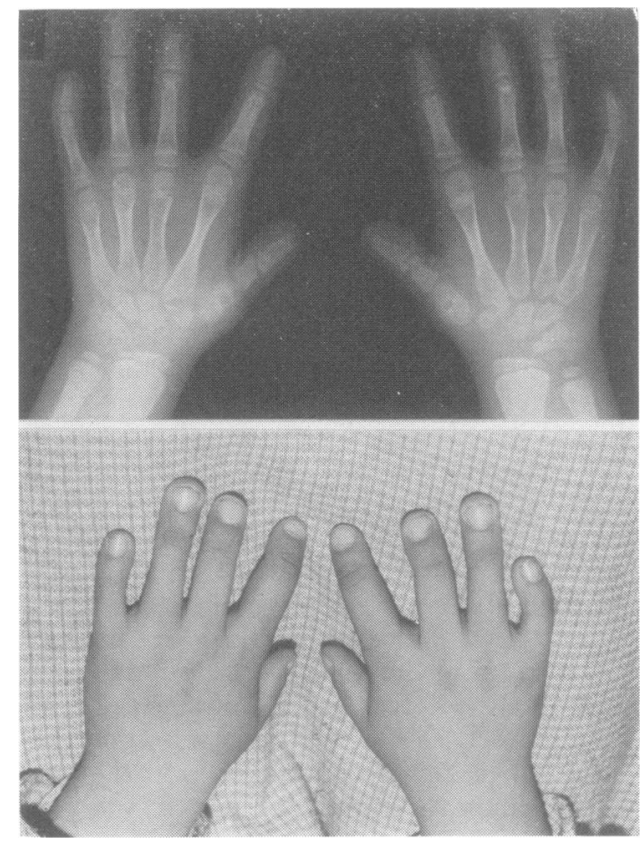

FIG 1 Clinical and radiological appearance of the hands of the 7-year-old girl. 


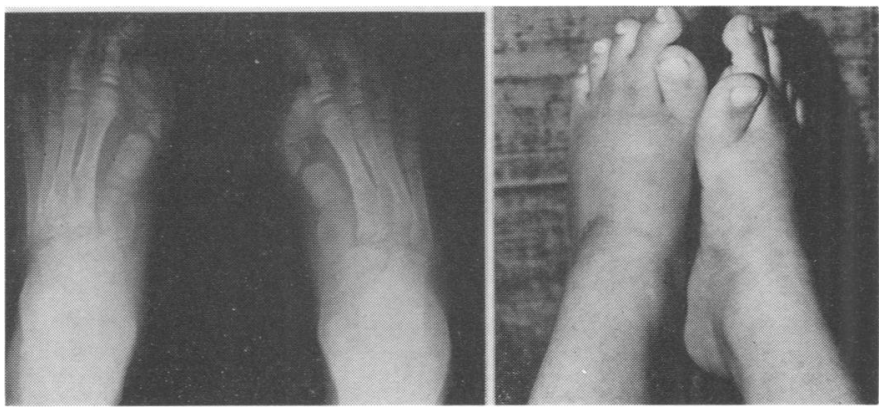

FIG 2 Clinical and radiological appearance of the feet of the 7-year-old girl.

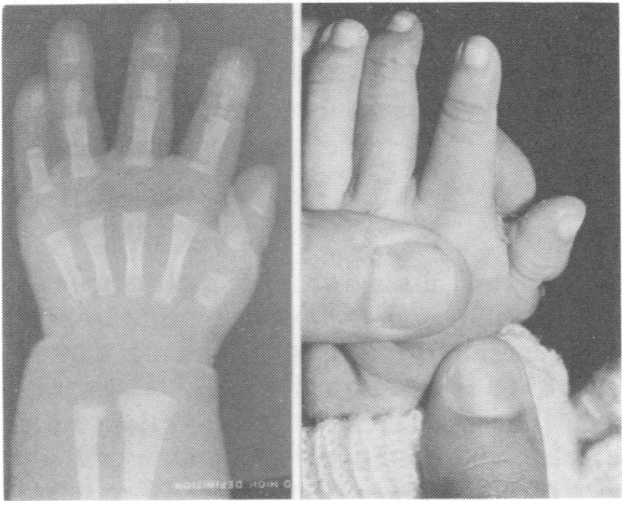

FIG 3 Clinical and radiological appearance of the hands of the 14-month-old brother.

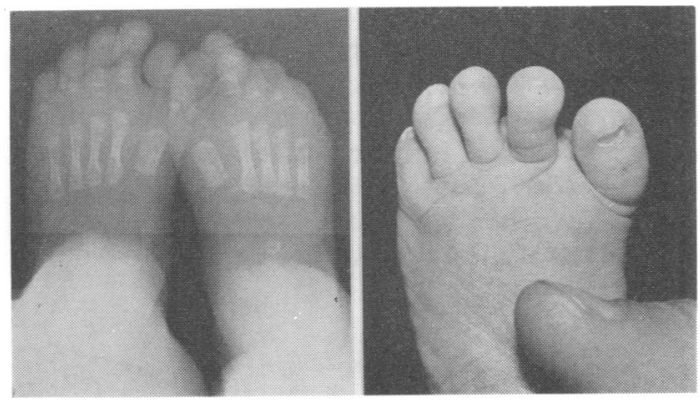

FIG 4 Clinical and radiological appearance of the feet of the 14-month-old brother.

\section{Discussion}

The Bell classification of brachydactyly is useful, but it is sometimes difficult to distinguish between types A1 and C. In type A1, the main findings are a broad hand with proportionate shortening of all the digits caused by short middle phalanges. In type $\mathrm{C}$ the shortening also affects the middle phalanges, especially of digits 2, 3, and 5, but Fitch ${ }^{2}$ differentiates the two as follows.
In type $\mathrm{A} 1$ the proximal phalanx of the thumb is short, whereas in type $\mathrm{C}$ it is the metacarpal which is particularly involved. In addition, in type A1 the third middle phalanx is longer than the fourth, whereas in type $C$ the fourth is not as severely affected as the third.

In the family reported here, the proximal phalanges of the thumb and big toe were short, as was the first metacarpal. The fourth middle phalanx is the least severely affected. Designation as type $C$ is therefore appropriate.

The inheritance pattern of type $\mathrm{C}$ brachydactyly has, to date, been reported to be uniformly dominant, but the presence of this abnormality in two sibs whose unaffected parents are consanguineous strongly suggests recessive transmission in this family. A striking feature in the older child was the bilateral duplication of the first proximal phalanx with preaxial projection of the more proximal fragment, resulting in valgus deformity of the big toe. This feature is described in type $\mathrm{C}$ brachydactyly. ${ }^{2}$

On clinical examination, the disproportionate shortening of the big toe was reminiscent of fibrodysplasia ossificans progressiva. However, the $x$-ray appearance was not typical, and ectopic bone formation was not present.

We are grateful to Carol Reeves and Sadie Pottinger for preparing the illustrations and manuscript, respectively.

\section{References}

1 Bell J. On brachydactyly and symphalangism. Treasury of Human Inheritance $1951 ; 5: 1-30$.

2 Fitch N. Classification and identification of inherited brachydactylies. J Med Genet 1979;16:36-44.

Requests for reprints to Dr J Burn, MRC Clinical Genetics Unit, Institute of Child Health, 30 Guilford Street, London WC1N 1EH. 